\title{
SCHOPENHAUER Y GRACIÁN: ARTE DE PRUDENCIA Y SABIDURÍA MUNDANA
}

\section{SCHOPENHAUER AND GRACIÁN: ARTE DE PRUDENCIA AND WORLDLY WISDOM}

\author{
JUAN DAVID MATEU ALONSO* \\ Universitat de València
}

\begin{abstract}
RESUMEN: El propósito de este trabajo es explicar algunos aspectos de la relación entre Arthur Schopenhauer y Baltasar Gracián. En primer lugar, muestro el desarrollo de la sabiduría mundana en la obra de Schopenhauer y el vínculo con el Oráculo manual y arte de prudencia de Gracián, traducido por Schopenhauer al alemán. En segundo lugar, intento hacer un balance de este vínculo teniendo en cuenta cuatro aspectos: a) la sindéresis y el arte de prudencia, b) la autarquía del individuo, c) la crítica a Maquiavelo y d) la cuestión ontológica. Por último, concluyo con algunas reflexiones sobre el moralismo moderno y su importancia para la filosofía sistemática de Schopenhauer.
\end{abstract}

PALABRAS CLAVE: Gracián, Schopenhauer, sabiduría, moralidad, sabiduría mundana.

ABSTRACT: The aim of this paper is to explain some aspects of the relationship between Arthur Schopenhauer and Baltasar Gracián. First of all, I try to show the development of worldly wisdom in Schopenhauer's work and its link with Gracian’s Oráculo manual y arte de prudencia, translated into German by Schopenhauer. After this, I would want to present some considerations about this link, taking into account four points: a) sindéresis and arte de prudencia, b) individual's self-government, c) the criticism of Macchiavelli and d) the ontological problem. Finally, I conclude with some reflections about the tradition of modern moralism and its relevance for Schopenhauer's systematic philosophy.

KEYWORDS: Gracián, Schopenhauer, wisdom, morality, worldly wisdom.

\footnotetext{
*David.Mateu@uv.es. Doctor en Filosofía por la Universitat de València. C/ Dr. Beltrán Bigorra, 11, 6. 46003 Valencia.
} 


\section{Introducción: la sabiduría vital en la obra de Schopenhauer}

En la obra schopenhaueriana se suelen destacar con cierta notoriedad el pesimismo y la metafísica de la voluntad, su estética del genio y la ética de la compasión. Cierto es también que sus escritos variados sobre la educación, la retórica, las mujeres, la tragedia, la psicología, etc., han cosechado asimismo cierta popularidad entre los lectores, pero en general se analiza la filosofía de Schopenhauer desde una óptica histórico-filosófica que lo sitúa en el diálogo sobre la naturaleza de la cosa en sí kantiana y en contraposición a Hegel, lo cual es totalmente acertado, pero habría que esbozar una ampliación de esta perspectiva, objetivo que quiero alcanzar mediante la relación de Schopenhauer con Gracián.

Así pues, el propósito de este trabajo es replantear la influencia y la vinculación entre Baltasar Gracián y Arthur Schopenhauer, para revisar la relación entre metafísica y moral en la filosofía de este último. En el caso de Schopenhauer, su sistema filosófico se asemeja, según su propia metáfora, a una ciudad de cien puertas que conducen a un pensamiento único, que se puede concretar en el concepto de voluntad como esencia última del mundo. Metafísica, teoría del conocimiento, estética y moral giran, en el sistema schopenhaueriano, alrededor de este eje conceptual, y sin embargo el propio Schopenhauer reconoce que cierto tipo de discurso filosófico que él practica, la sabiduría mundana sobre la vida, una reflexión mundana moral a la vez que pragmática, supondría una suspensión de ese sistema y de la perspectiva general que anima su filosofía. La cuestión es, pues, la articulación de la metafísica general con esta sabiduría mundana, una forma de filosofía en la que la lectura de Gracián juega un papel clave.

Si asumimos una visión crítica de la propia filosofía schopenhaueriana, en particular, el punto de vista que nos sugiere Nietzsche al respecto en Humano, demasiado humano, creo que podemos ofrecer una interpretación más rica y global de la filosofía de Schopenhauer. Esta lectura de raigambre nietzscheana está dirigida a mostrar las raíces de la ontología, la teoría del conocimiento o la ética de Schopenhauer. Sobre esta relación de Schopenhauer con la tradición moralista, y sobre todo con el moralismo barroco español y el dieciochesco francés, Nietzsche nos ofrece una consideración crítica que cabe tener en consideración, más aún cuando el propio Nietzsche fue un asiduo lector de esta tradición de pensamiento, como se atestigua en 
Humano, demasiado humano. Esta reflexión tiene que ver con el concepto central de la filosofía de Schopenhauer: la noción de voluntad.

Los filósofos se han apropiado en todas las épocas de las sentencias de los examinadores de humanos (los moralistas) y las han arruinado en tanto que las tomaron incondicionalmente y quisieron probar como necesario aquello que para los moralistas sólo se entendía como indicación aproximada o incluso como verdad de una década concerniente a un país o a una ciudad. Así encontraremos como fundamento de las famosas teorías de Schopenhauer sobre la primacía de la voluntad sobre el intelecto, sobre la inmutabilidad del carácter, sobre la negatividad del placer — que, tal y como él las entiende, son errores - dichos populares que han planteado los moralistas. Ya la palabra "voluntad", que Schopenhauer transformó en referencia común de muchos estados humanos y con la que rellenó un hueco del lenguaje, con gran ventaja para sí mismo en tanto que era moralista, [...] esta voluntad se ha convertido en una metáfora poética cuando se afirma que todas las cosas en la naturaleza tienen voluntad (Nietzsche, KSA, 2, 382). ${ }^{1}$

Esta crítica genealógico-conceptual se refiere la noción central de la metafísica de Schopenhauer, quien no habría hecho más que transponer la idea de voluntad humana de las reflexiones de los moralistas a toda la naturaleza, de forma incondicional y universal. Así ha cometido “el pecado original de los filósofos”, título del aforismo, produciendo una metáfora que supone «una desgracia para la ciencia» (Nietzsche, KSA, 2, 382) en tanto que acaba convirtiéndose en una moda, en un concepto que sirve para explicarlo todo sin explicar nada en concreto, provocando una «falsa reificación» de la multitud de referentes originarios, los diversos estados anímicos de los humanos. Ahora bien, ¿'supone esta crítica un rechazo radical de Schopenhauer? En absoluto. Nietzsche no reniega en Humano, demasiado humano de sus elogios a Schopenhauer en la tercera intempestiva, Schopenhauer como educador, sino que supone una valoración de la que

\footnotetext{
${ }^{1}$ Para referirme a las obras de Nietzsche utilizo la edición de Colli y Montinari conocida como KSA, citada en la bibliografía final. En lo que concierne a las referencias a Schopenhauer y Gracián utilizo el siguiente sistema de abreviaturas. En el caso de Schopenhauer las siglas son las siguientes: WWV para El mundo como voluntad y representación, PP para Parerga y Paralipómena, en cuyo primer volumen se encuentran los "Aforismos para la sabiduría de la vida", HN para Der handschriftliche Nachlass (El legado manuscrito) y GB para Gesammelte Briefe (Cartas completas). Para las obras de Gracián me referiré al Oráculo manual y arte de prudencia mediante OP, siguiendo el número del aforismo, y a $E l$ Criticón con una C, parte, «crisi» y página. En el caso de Schopenhauer añado entre corchetes la página de la versión castellana citada en bibliografía; las traducciones de las citas son mías.
} 
resulta bien parada la vertiente moralista (aforística y sapiencial) de Schopenhauer, frente a su metafísica de la voluntad:

Schopenhauer, cuyo gran conocimiento para lo humano y lo demasiado humano, cuyo originario sentido para los hechos no ha sido poco estorbado por la moteada piel de leopardo de su metafísica (que se le ha de quitar para descubrir debajo un auténtico genio moralista) (Nietzsche, KSA, 2, 395).

Además del elogio del genio moralista de Schopenhauer, seguramente basado en su conocimiento de la tradición clásica tan apreciada por Nietzsche, éste plantea la independencia de la eudemonología o teoría de la felicidad respecto a la piel felina de la metafísica. Esta tesis de Nietzsche es matizable, puesto que la cuestión de la coherencia de Schopenhauer en lo que se refiere a la articulación de la teoría de la felicidad o eudemonología de los Aforismos sobre la sabiduría de la vida (como afirmación moderada de ésta) con el resto de su ética y su ontología constituye un problema por sí mismo. ${ }^{2}$ Es el propio Schopenhauer quien se encarga de apuntar esta dificultad en la introducción a esos aforismos:

Ésta [la eudemonología], precisamente, descansa sobre el error innato, cuya reprensión inaugura el capítulo 49 del segundo volumen de mi obra principal. En consecuencia, para poder elaborar una tal eudemonología, he tenido que prescindir completamente de la más alta perspectiva metafísica y ética a la que conduce mi verdadera filosofía. Por consiguiente, toda la discusión que aquí se va a ofrecer en cierta medida descansa sobre una acomodación [Ackommodation], en tanto que permanece bajo la perspectiva empírica habitual y se aferra a su error. Por ello, su valor sólo puede ser condicional, puesto que incluso la palabra eudemonología es tan sólo un eufemismo (PP, I, 313 [331]).

\footnotetext{
2 Robert Zimmer ha utilizado una metáfora espacial para resaltar la diferencia entre la metafísica pesimista de El mundo y los aforismos mundanos de Parerga y Paralipómena: mientras que la primera adopta una interpretación "vertical” sobre el mundo y la naturaleza humana buscando en su interior, en la segunda el punto de vista es "horizontal”, observando el trato humano en sociedad (Zimmer, 2009, 46).
} 
Sin embargo, esta afirmación debe ser puesta ella misma en suspenso. Como ha indicado Rüdiger Safranski, tanto la metafísica como la eudemonología (que aquí expone Schopenhauer con reservas) presuponen el mismo problema, el insaciable afán de la voluntad. De este modo, también en estos aforismos de Parerga y Paralipómena emerge de forma velada la cuestión de la negación de la voluntad, por lo que no serían tan independientes del resto de su metafísica como insistiría Schopenhauer. ${ }^{3}$

En una línea semejante, también Volker Spierling señala que tanto la ética de la compasión como la sabiduría mundana (o eudemonología) se sustentan en una idea básica: «La convicción de Schopenhauer, según la cual todo placer y toda felicidad son negativos y que, por el contrario, el dolor es positivo, es de la mayor importancia tanto para los Aforismos como para su obra completa» (Spierling, 1994, 213). Si atendemos a una perspectiva histórico-biográfica, los Aforismos, aunque publicados en 1851, venían elaborándose por parte de Schopenhauer al menos desde 1814, en unos esbozos coetáneos de las reflexiones que luego conformarían su primera y principal obra, El mundo como voluntad y representación.

Mi intención en este trabajo es reivindicar la relevancia de la eudemonología o teoría de la felicidad de Schopenhauer en el conjunto de su obra y destacar la gran influencia de Baltasar Gracián en la configuración de dicha eudemonología. Ciertamente, como han apuntado Spierling y Hübscher, ${ }^{4}$ la temática propia que se desarrolla en los Aforismos, tiene su punto de referencia en los textos póstumos de alrededor de 1826-1830 (que luego se han publicado como El arte de ser feliz), época en que Schopenhauer trata de buscar una teoría de la felicidad o eudemonología y redacta un esbozo de un tratado sobre el honor (HN, III, Adversaria, §69, 472-496), texto que encontrará su culminación en el apartado de los Aforismos dedicado a tal cuestión. Precisamente en ese momento (1826-1830), Schopenhauer había vuelto de uno de sus viajes a Italia y estaba preparando la traducción del Oráculo manual y arte de prudencia

\footnotetext{
3 «La amortiguación de la voluntad pertenece de antemano a esta autarquía. Ha de predominar una capacidad de meditación que no proviene sólo de la sabiduría de la vida obligada por el principio de realidad, sino que contiene ya una cierta añadidura de negación de la voluntad. En esta medida Schopenhauer presupone en cierto sentido aquella "perspectiva metafísico-ética" que pretende ciertamente poner entre paréntesis» (Safranski, 2001, 496). En la misma línea de conexión fuerte entre eudemonología y metafísica apuntaría Robert Zimmer (Zimmer, 2009, 46).

4 Véase lo que indica Hübscher en su prólogo al volumen III del Nachlass (HN, III, XI y ss.), así como en los comentarios sobre Gracián en el prólogo al volumen IV de la misma edición (HN, IV, 2, p. x y ss.).
} 
de Gracián (había empezado a aprender castellano a partir de 1825$){ }^{5}$ La coincidencia es significativa, pues tanto el estilo como las ideas expresadas en los aforismos del jesuita tienen una fuerte influencia en el pensamiento de Schopenhauer. ${ }^{6}$

\section{Balance de una influencia: Gracián y Schopenhauer}

El pensamiento schopenhaueriano sobre la felicidad humana y la vida social está claramente marcado por el jesuita Baltasar Gracián, de quien tradujo el Oráculo manual y arte de prudencia (OP en citas), precisamente en los años en los que tomaban forma los Aforismos sobre la eudemonología. No es éste el lugar para emprender una investigación a fondo sobre las fuentes hispanas del pensamiento de Schopenhauer, que abarcan desde Huarte de San Juan o Cervantes hasta Larra, pasando por Lope de Vega, Calderón, Quevedo o el propio Gracián, aunque me centraré brevemente en la presencia de este último, y en particular en cuatro aspectos de la influencia sobre Schopenhauer que pueden dar pie a ciertas analogías entre ambos: a) la gran sindéresis y el arte de prudencia, b) el dominio de sí y la autarquía, c) la crítica a Maquiavelo y d) la cuestión ontológica.

Del jesuita aragonés tradujo Schopenhauer anónimamente el Oráculo manual, pese a las dificultades para encontrar editor, y proyectó una traducción de El Criticón, aunque ésta no llegó a concretarse. Cabe precisar que la época en la que Schopenhauer se dedicó a la tarea de traducción de Gracián coincide con la de los esbozos de su eudemonología, finales de los 20 y principios de los 30 del siglo XIX, cuando huyó de Berlín asustado por la epidemia de cólera que afectaba a la capital prusiana (epidemia que acabaría con la vida de Hegel) y se estableció en Frankfurt a.M. En una carta (abril de 1832) al hispanista y editor de Calderón y Cervantes en alemán, Johann Georg Keil, Schopenhauer le confiesa que se ha «españolizado» y que lleva desde 1825 ocupado con el castellano, ofreciéndole la traducción de El Criticón (C en citas): «Mi autor preferido es este escritor filosófico Gracián: he leído todas sus obras y su Criticón es para mí uno

\footnotetext{
${ }^{5}$ Para una cronología más precisa véase la introducción de A. Hübscher al volumen IV, 2, de Der handschriftliche Nachlass, donde explica que el primer intento de traducción (1828) fue abandonado por la negativa del editor Brockhaus y luego retomó la traducción en 1831, finalizando en 1832. Véase también a propósito de la traducción el libro de Losada Palenzuela citado en la bibliografía.

6 Para Hans Blumenberg el atractivo que siente Schopenhauer por Gracián (por El Criticón especialmente) se debería a que ambos son pensadores «de talento alegórico» (Blumenberg, 2000, 115).
} 
de los más estimados libros en el mundo entero; con gusto lo traduciría, si encontrase un editor para ello» $(\mathrm{GB}, 131)$.

No obstante, la obra de Gracián que tradujo a Schopenhauer fue el Oráculo manual y arte de prudencia, cuya traducción sólo vio la luz dos años después de la muerte de Schopenhauer y bajo un curioso pseudónimo, Felix Treumund (Félix Bocafiel). Cabe recordar que el Oráculo consiste en 300 aforismos que condensan el pensamiento de Gracián, aunque el proyecto inicial lo iban a componer tan sólo los 100 primeros aforismos, de ahí que alrededor de ese número se produzca una especie de concentración conclusiva de ideas.

Después del rechazo de Brockhaus, fue el hispanista Keil quien buscó editor para este “trabajo bastardo”, en palabras del propio Schopenhauer (GB, 135). El éxito de esta traducción lo atestiguan las numerosas reediciones de este libro, que llegan hasta la actualidad, y también el hecho de que Schopenhauer consiguiera poner de relieve el calado filosófico de la obra de Gracián en Alemania y por difusión en el resto de Europa en la segunda mitad del siglo XIX (Vossler, 1935, 344). Pese a las declaraciones de Schopenhauer y a la impronta que se puede percibir en sus textos sobre la sabiduría mundana, hemos de tener cierta cautela respecto a la afinidad con Gracián, pues quizá él mismo quiso ver más cercanía de la que había en realidad, como indica Karl Vossler (Vossler, 1935, 346). ${ }^{7}$

\subsection{La gran sindéresis y el arte de prudencia.}

En primer lugar, atendamos a los dos conceptos centrales de este apartado, prudencia y sindéresis. En el caso de la prudencia, que Schopenhauer tradujo como Weltklugheit, inteligencia o astucia mundana, muchos comentaristas, como Aranguren, señalan que ya no se puede entender desde las coordenadas de la virtud cardinal de la ética medieval, sino que en Gracián, y en concreto en el Oráculo, adquiere un valor pragmático, casi utilitarista. ${ }^{8}$ La prudencia en Gracián (OP, 21 y 64, por ejemplo) ${ }^{9}$ es

\footnotetext{
${ }^{7}$ Hübscher, editor de los fragmentos póstumos de Schopenhauer, comenta que la conexión se centra sobre todo en la desconfianza hacia la vida social y la reivindicación de un individuo autárquico (Hübscher, 1985, XII).

${ }^{8}$ Para un repaso histórico del concepto véase el Diccionario de conceptos de Baltasar Gracián, pp. 206210.
} 
más un instrumento para conseguir un objetivo pragmático y lograr la propia dicha que la excelencia característica de toda otra virtud. En este sentido, siguiendo a Aranguren, en Gracián se produce una separación entre ética y eudemonología (moral mundana y pragmática) semejante a la que plantea Schopenhauer. ${ }^{10}$ La prudencia es un arte, no un saber o ciencia, y por ello se trata de una cuestión aproximativa y probable. En definitiva, como ha argumentado Elena Cantarino, entre otros con el Oráculo se produce una extrapolación de una razón de Estado a una razón de estado del individuo, a una reflexión sobre el gobierno de sí (p. ej. Cantarino, 2003, 131-132).

Ahora bien, el concepto que creo fundamental para la reflexión eudemonológica es el de sindéresis. Concepto de raíz griega que viene a significar buen sentido o juicio, se convierte para Gracián en la clave de su teoría de la vida feliz, ${ }^{11}$ introduciendo en ella un fuerte componente racionalista. En cierto modo, la noción de sindéresis sirve de fundamento a la prudencia, como se puede colegir de algunos aforismos del Oráculo:

De la gran sindéresis. Es el trono de la razón, basa de la prudencia, que en fe della cuesta poco el acertar. [...] Todas las acciones de la vida dependen de su influencia, y todas solicitan su calificación, que todo ha de ser con seso. Consiste en una conatural propensión a todo lo más conforme a razón, casándose siempre con lo más acertado (OP, 96).

En este aforismo se define la sindéresis como una propensión hacia la decisión más racional posible, aunque matizando que aquí la razón se adecua a la situación, al contexto, produciéndose algo así como una adaptación prudencial de la máxima racional

\footnotetext{
${ }^{9}$ Los textos de Gracián se tomarán de las ediciones de la colección Letras Hispánicas de la editorial Cátedra; en el caso del Oráculo manual y arte de prudencia se utilizará la abreviatura OP, seguida del número del aforismo en cuestión. Las referencias de El Criticón se indicarán con una C, seguida de la parte, el número de la crisi y el número de página.

10 Aranguren argumenta que en la obra de Gracián se pueden distinguir tres planos: el pragmáticoutilitario de El Héroe, El Discreto o el Oráculo, el ético-filosófico de El Criticón y el religioso del Comulgatorio (Aranguren, 1999, 169-170). Por su parte, Maravall ha afirmado que se produce un paso de una perspectiva moral a una óptica moralística en la obra de Gracián (Maravall, 1986, 350).

${ }^{11}$ Marcin (2006) establece, de una manera poco crítica a mi juicio, una fuerte analogía entre la sindéresis en Tomás de Aquino y Schopenhauer; Elena Cantarino (2011) plantea una somera genealogía del concepto que permite apreciar los desplazamientos y la centralidad del sentido gracianesco (como cuidado instintivo de uno mismo) para Schopenhauer, ya alejado de la noción tomista del término (como hábito que contiene los primeros principios prácticos o luz de la conciencia para distinguir el bien y el mal). Novella Suárez, siguiendo a Arturo del Hoyo, habla de una secularización de la prudencia tomista en el concepto gracianesco de prudencia (Novella, 2003, 206).
} 
de la acción. Además de esta racionalidad práctica situada, el texto incide en la validez universal de la sindéresis en todos los ámbitos de la vida y se trata de una capacidad innata o connatural al ser humano que puede ir mejorándose y potenciándose a lo largo de toda la vida.

Quizá otra forma de entender este concepto de sindéresis sea, indirectamente, atendiendo a la propia traducción del término al alemán que propone Schopenhauer; éste la denomina como la Urteilskraft, ${ }^{12}$ esto es, el juicio o discernimiento en sentido genérico, pues, aunque eminentemente práctica, la sindéresis como "buen juicio" también puede referirse a cuestiones estéticas. Esto es, se trata de una cualidad cuasi pre-racional, instintiva en cierto sentido, innata, y que también sirve de guardiana de la propia vida.

Para delinear el contenido de este concepto, me apoyaré primero en algunos textos de Schopenhauer y luego en la definición ofrecida por Gracián. En primera instancia quisiera destacar la función de intermediación entre dos facultades intelectuales, el entendimiento y la razón, que desempeña el juicio o Urtheilskraft: «el juicio, que consiste en la facultad de trasladar correcta y exactamente el conocimiento intuitivo a la conciencia abstracta, y por tanto es el mediador entre entendimiento y razón» (WWV, I, §14, 109 [115]). Esto mismo aparece en el segundo volumen de El mundo como voluntad y representación (WWV, II, §7, 105-106 [119-120]), pero con algunas variaciones destacables; además de insistir en la necesidad del juicio para el progreso de las ciencias y el fundamento de éstas, Schopenhauer extrapola su importancia del plano epistemológico al plano vital: «No menos en la vida práctica tiene que ser decisivo el juicio [die Urtheilskraft] en todas las resoluciones fundamentales y decisiones principales» (WWV, II, §7, 105 [120]). La sombra de Gracián se percibe en estos textos de WWV, II, puesto que en ellos vincula Schopenhauer el juicio con el ingenio y la agudeza: «Manifestaciones del juicio son también el ingenio [Witz] y la agudeza [Scharfsinn]: en aquél es reflexivo, en ésta actúa subsumiendo» (WWV, II, §7, $105[121])$.

Pero precisamente es en los Aforismos de PP, I donde podemos encontrar una segunda labor de mediación propia del juicio que nos permite también avanzar en nuestro desarrollo. Desde una óptica pragmática y mundana, el juicio, no ya sólo como

12 Véase Cantarino, 2011, pp. 57-58 para otras variantes de la traducción. 
facultad, sino como enunciado, puede verse atrapado también entre las dos facultades principales del ser humano, el intelecto (el razonamiento) y la voluntad (la pasión y el sentimiento). La sabiduría mundana aconseja que los juicios y valoraciones derivados de la facultad de juzgar no sean fruto de la excitación de la voluntad (PP, I, 454-455 [478]). En este contexto, Schopenhauer recuerda que la prudencia exige la independencia del juicio respecto a la voluntad (luego volveremos al tema de la prudencia en Schopenhauer), con lo que de nuevo nos encontramos con el concepto metafísico fundamental en plena argumentación sobre la sabiduría mundana.

Ahora bien, para completar nuestro propósito de vincular la sindéresis de Gracián con el juicio (Urtheilskraft) de Schopenhauer podemos recurrir también a los propios textos de Gracián, entre los que destaca el aforismo 24, donde se destaca el control sobre la imaginación que ha de ejercer la sindéresis:

Templar la imaginación. Unas vezes corrigiéndola; otras ayudándola, que es el todo para la felicidad, y aun ajusta la cordura. [...] [La imaginación] Representa a unos continuamente penas, hecha verdugo casero de necios. Propone a otros felicidades y aventuras con alegre desvanecimiento. Todo esto puede, si no la enfrena la prudentísima sindéresis (OP, 24).

Así pues, la sindéresis ha de servir de correctora y auxiliar de la imaginación, lo cual parecería un papel secundario, pero no lo es tanto si se tiene en cuenta que no se trata de someter sólo a la imaginación, sino que asume asimismo una función de control que ha de llevar a cabo también sobre la racionalidad. De este modo, la sindéresis media con la imaginación y la razón para llegar a buen puerto.

En orden a explicar la función de la sindéresis, el propio Gracián se sirve de la metáfora de la balanza en este caso no para corregir la imaginación y la cordura, sino como equilibrio entre artificio y naturaleza, evitando que el sujeto caiga esclavo de las “impresiones” que no serían otra cosa que afectos, pasiones, sentimientos y deseos:

No rendirse a un vulgar humor. Hombre grande el que nunca se sugeta a peregrinas impressiones. Es lición de advertencia la reflexión de sí: un conocer su disposición actual y prevenirla, y aun decantarse al otro extremo para hallar, entre el natural y el 
arte, el fiel de la sindéresis. Principio es de corregirse el conocerse; que ai monstros de la impertinencia: siempre están de algún humor y varían afectos con ellos; y arrastrados eternamente desta destemplança civil, contraditoriamente se empeñan. Y no sólo gasta la voluntad este excesso, sino que se atreve al juizio, alterando el querer y el entender (OP, 69).

Este texto expone claramente que la reflexión de sí, el conocimiento de uno mismo, es la clave para el correcto ejercicio de la sindéresis. La reivindicación del autoconocimiento permite vincular esta tesis con la teoría del carácter adquirido de Schopenhauer, relación que atestigua también Werner Krauss en su libro sobre La doctrina de la vida según Baltasar Gracián. ${ }^{13}$

Pero además de esta vinculación de la reflexión de sí con el carácter adquirido como auto-conocimiento de Schopenhauer, el aforismo anterior introduce una pareja conceptual crucial: voluntad y juicio, o de otro modo, querer y entender. La sindéresis no sólo tiene que hacer frente a los excesos que puedan afectar a la voluntad, sino que el desequilibrio de las “impresiones” (afectos) también afecta al juicio o entendimiento. ${ }^{14}$ Así, Gracián pone en juego una dualidad que Schopenhauer explotará al máximo, aunque hay que tener en cuenta que en todo momento Gracián se atiene al sentido subjetivo de estos conceptos, es decir, se refiere a voluntad y juicio como facultades subjetivas de todo individuo humano, sin reificarlos, como le criticará Nietzsche a Schopenhauer respecto a la noción de voluntad (por ejemplo en el texto citado de Humano, demasiado humano, KSA, 2, 382).

\footnotetext{
13 «Gracián considera que la persona es un producto de la experiencia y de la formación. [...] Visto desde este punto de vista, el concepto moderno de carácter comparte las propiedades del "ser-persona"» (Krauss, 1962, 201). En las pp. 194-203 de su libro, Krauss expone cómo el concepto de persona de Gracián puede equipararse a la noción kantiana de carácter, y por extensión podemos añadir a la de Schopenhauer, en tanto que éste lo toma del filósofo de Königsberg. Krauss, sin embargo, reconoce que el concepto de carácter no está tan perfilado en Gracián como lo estará en Kant o Schopenhauer (Krauss, 1962, 202-203).

14 «Buenos dictámenes. Nácense algunos prudentes: entran con esta ventaja de la sindéresis conatural en la sabiduría, y assí tienen la metad andada para los aciertos. Con la edad y la experiencia viene a sazonarse del todo la razón, y llegan a un juicio mui templado. Abominan de todo capricho como de tentación de la cordura, y más en materias de estado, donde por la suma importancia se requiere la total seguridad» (OP, 60). Cabe señalar que la sindéresis no sólo previene contra los "caprichos" o afecciones de la voluntad, sino también contra las tentaciones de la cordura. Ya en el aforismo 24, citado supra, había indicado Gracián que la sindéresis llegaba incluso a ajustar la cordura, evitando sus posibles excesos que la podrían llevar a convertirse en su contrario. Destaco también que Gracián remita esta cuestión al ámbito político (ver infra las críticas a Maquiavelo).
} 
En cierto sentido, sobre todo por lo que se refiere a la cuestión del autoconocimiento y de la reflexión de sí, en Gracián se produce una convergencia de temas clásicos como el del nosce te ipsum, ${ }^{15}$ o la aurea mediocritas de Horacio, poeta que le sirve a Schopenhauer como un prisma para descomponer las diferentes aplicaciones y situaciones que abarcan los aforismos de Gracián y su asimilación y transformación en su propia eudemonología.

Así como hemos desentrañado algunos aspectos de la sindéresis, no podemos dejar de lado una de las máximas principales que se siguen de ella y que deriva también de la prudencia clásica, la búsqueda del término medio con el fin de ejercer la virtud y lograr la felicidad. Gracián sigue en cierto modo el esquema tradicional aristotélico en el tratamiento de la cuestión del término medio o aurea mediocritas latina, aunque su presentación literaria permite establecer una jerarquía de las virtudes:

Mira aquel otro de los siete de la Grecia eterniçado sabio por sola aquella sentencia: Huye en todo la demasía; porque siempre dañó más lo más que lo menos. Estaban de relieve todas las virtudes con plausibles empressas en targetas y roleos. Començaban por orden, puesta cada una en medio de sus dos viciosos estremos, y en lo baxo la Fortaleza, assegurando el apoyo a las demás, recostada sobre el cogín de una coluna media entre la Temeridad y la Cobardía. Procediendo assí todas las otras, remataba la Prudencia como reina y en sus manos tenía una preciosa corona con este lema: Para el que ama la mediocridad de oro (C, I, 5, 122). ${ }^{16}$

En conclusión, la prudencia como racionalidad pragmática se fundamenta en la sindéresis, definida como esa propensión innata hacia lo mesurado y racional, pero teniendo como objetivo el llegar a ser persona que se propone en el primer aforismo del Oráculo. Así, para Gracián la sindéresis opera como una condición necesaria de ese desarrollo del carácter personal, del mismo modo que Schopenhauer señala que sin un conocimiento intuitivo previo, esa custodia natural que constituye la sindéresis, de nada

\footnotetext{
15 Ver también C, I, 9, 188.

16 Moraleja ha señalado que la razón prudencial de Gracián está mucho más ligada a un saber práctico aproximativo que a un cálculo en sentido estricto, pues tiene en consideración factores inciertos que se presentan en la decisión, a diferencia del racionalismo del Barroco francés (Moraleja, 1999, 90-91). De aquí que se hable de "arte” de prudencia, incidiendo en el sentido aproximativo de tal forma de saber.
} 
sirven los 300 aforismos del Oráculo para el cultivo de uno mismo, aunque uno los memorice (WWV, II, §7, 89 [106]).

Para refrendar el sentido que Schopenhauer le da a la prudencia de Gracián, podemos remitir al uso del concepto de Weltklugheit, con el que traduce "prudencia”, en algunos de sus textos y que podría entenderse a su vez como "astucia o inteligencia mundana”. Este concepto se contrapone al conocimiento abstracto y requiere de práctica y experiencia (WWV, II, §7, 90 [106]). Además, esta prudencia como “sabiduría mundana” sería inferior, según Schopenhauer, en los individuos con mayor inteligencia natural y mayor en la gente menos dotada, estableciendo una proporcionalidad inversa entre prudencia o sabiduría mundana (según las traducciones al castellano de Weltklugheit en la obra de Schopenhauer) y talento (Begabung) (PP, I, 444 [466]). En el apartado dedicado a las máximas (Cap. V de los Aforismos), Schopenhauer le da cierto contenido al concepto y remite a consejos como guardar silencio o mantener una cierta distancia sentimental como medida de prevención (PP, I, 456-457 [480]). Esto último nos permite enlazar con el siguiente aspecto: la autarquía del hombre mundano.

\subsection{EI dominio de sí y la autarquía}

Como se expone en el aforismo 89 del Oráculo, la condición del dominio de sí es el conocimiento de uno mismo, de modo que sólo aquel que ha podido ejercitar la reflexión y la sindéresis sobre sí, puede llegar a conseguir la autarquía del sabio que plantea Gracián y que asume Schopenhauer (PP, I, 317-318 [336-337]), en la línea de la tradición clásica: «No puede uno ser señor de sí si primero no se comprehende. Ai espejos del rostro, no los ai del ánimo: seálo la discreta reflexión sobre sí. Y quando se olvidare de su imagen exterior, conserve la interior para enmendarla, para mejorarla» $(\mathrm{OP}, 89){ }^{17}$

Como dirá en el aforismo 225, este conocimiento de sí empieza por lo negativo: cada uno ha de conocer su defecto principal para comenzar por él en la labor de construcción y mejora de uno mismo. El individuo, por tanto, se enfrenta al mundo y a

17 «Hombre en su punto. No se nace hecho: vase de cada día perficionando en la persona, en el empleo, hasta llegar al punto del consumado ser, al complemento de prendas, de eminencias» $(\mathrm{OP}, 6)$. 
la sociedad; ${ }^{18}$ el moralismo barroco de Gracián plantea una escisión entre sujeto y sociedad mundana que Schopenhauer asume en toda su radicalidad. Como diría Chamfort, en una cita que recoge Schopenhauer para encabezar sus Aforismos: «La felicidad no es cosa fácil. Es muy difícil encontrarla en nosotros e imposible encontrarla en otra parte». ${ }^{19}$

En toda esta cuestión del dominio de sí que ha de seguir al conocimiento de uno mismo, se puede encontrar la sombra del estoicismo que tanto influyó en el Siglo de Oro, y así lo atestiguan algunos aforismos de Gracián en los que se insiste en la liberación de los afectos y pasiones (impresiones, en su terminología):

Hombre inapassionable, prenda de la mayor alteza de ánimo. Su misma superioridad le redime de la sugeción a peregrinas vulgares impresiones. No ai mayor señorío que el de sí mismo, de sus afectos, que llega a ser triunfo del alvedrío (OP, 8).

Saber abstraher, que si es gran lición del vivir el saber negar, mayor será saberse negar a sí mesmo, a los negocios, a los personages (OP, 33).

De hecho, este último aforismo permite establecer el tránsito a la teoría de la negación de la voluntad de Schopenhauer, así como el primero posee también un cierto tono ascético, aunque el propio Gracián no era amigo de la ascética radical ni cristiana ni estoica. ${ }^{20}$ En cualquier caso, es innegable la presencia de Séneca en el pensamiento de Gracián y aquí resuena la máxima también utilizada por Schopenhauer en sus Aforismos según la cual si tibi vis omnia subjicere, te subjice ratione, «si quieres someter a ti todas las cosas, sométete tú mismo a la razón» (Séneca, Epístolas morales a Lucilio, 37, 4).

Abundando en la presencia del estoicismo, habría que señalar que la única fuente citada en todo el Oráculo es Epicteto, en el aforismo 159, donde se remite a su máxima sustine et abstine, poniéndose el acento en la primera parte de ésta para recordar al lector que hay que saber sufrir y soportar las necedades de los otros sin dejarse llevar por los propios impulsos. Precisamente esta forma de contención en el decir y el hacer

18 Sobre el individualismo de Gracián, véase Maravall, 1984, 366-367.

19 Chamfort, Maximes et pensées. Caractères et anecdotes. Paris: Gallimard, 1970, p. 300.

20 Ver la página 59 de la introducción al Oráculo manual y arte de prudencia, por parte de Emilio Blanco. 
como dominio de sí es explicitada en los aforismos 179 y 222, y en concreto en el 179 se produce una torsión de esta temática, pues no sólo se recomienda la contención, sino incluso la ocultación e inversión entre aquello que se ha de decir y lo que se tiene que hacer: «La retentiva es el sello de la capacidad. [...] En la templança interior consiste la salud de la prudencia. [...] Las cosas que se han de hazer no se han de dezir, y las que se han de dezir no se han de hazer» (OP, 179).

En definitiva, la finalidad de la sindéresis no es otra que el logro del ideal clásico de la autarquía, aunque, como ha indicado Krauss, Gracián se propone lograr el dominio de las pasiones, no su erradicación (Krauss, 1962, 194), de tal modo que no asumiría una posición ascética. De la misma manera, Schopenhauer ha insistido en la diferencia entre sus Aforismos sobre la sabiduría de la vida, en los que está claramente inspirado por Gracián y no llega a la defensa del ascetismo, y su ética de la compasión, coronada por la mística ascética.

\subsection{La crítica a Maquiavelo}

En Gracián, como en otros autores hispanos de tratados políticos del Siglo de Oro, como Quevedo o Saavedra Fajardo, se puede encontrar una crítica a Maquiavelo por su propuesta de convertir la política en una disciplina autónoma desligada de toda moral y religión (Krauss, 1962, 118 y ss.). Es interesante referir la crítica de Gracián a Maquiavelo, porque éste tendrá una notable importancia en las reflexiones políticas de Schopenhauer, y se verá cómo este último no podría admitir las críticas de Gracián al autor de El príncipe, aspecto que nos servirá para relativizar la cercanía entre Schopenhauer y Gracián.

La cuestión de fondo en esta polémica sería la relación entre política y religión. En cierto sentido, Gracián compartiría con Maquiavelo el realismo político que atiende a los hechos consumados y prescribe estrategias concretas para el logro de fines políticos particulares, pero no admitiría la total independencia de la política respecto a la religión. $^{21}$

21 «Tanto Maquiavelo como Gracián representan -si bien con distinto grado- el realismo político de la época. No obstante, mientras en Maquiavelo las premisas éticas y religiosas desaparecen o se subordinan a principios de utilidad y éxito, en la figura del jesuita esto jamás ocurre con la radicalidad con que se 
Así pues, la crítica a Maquiavelo está cargada de una tonalidad religiosa, no tanto de una crítica a su visión de la política como tal. No obstante, en el texto de El Criticón donde se ataca a Maquiavelo las razones también apuntan a una crítica ética y a una cuestión pragmática:

¿Quién piensas tú que es este valiente embustero? Éste es un falso político llamado el Maquiavelo, que quiere dar a beber sus falsos aforismos a los ignorantes. ¿ंNo ves cómo ellos se los tragan, pareciéndoles muy plausibles y verdaderos? Y, bien examinado, no son otro que una confitada inmundicia de vicios y de pecados: razones, no de Estado, sino de establo. Parece que tiene candidez en sus labios, pureza en su lengua, y arroja fuego infernal que abrasa las costumbres y quema las repúblicas. Aquellas que parecen cintas de sedas son las políticas leyes con que ata las manos a la virtud y las suelta al vicio $(\mathrm{C}, \mathrm{I}, 7,165)$.

En primer lugar, la burla que equipara el Estado al establo indica la reducción de los sujetos políticos humanos a meros animales que hay que domar para su uso por parte de los gobernantes, con lo que se plantea una crítica de cariz antropológico y moral. En segundo lugar, no sólo se le reprocha la desatención respecto a la religión, sino la corrupción de las costumbres y la atadura política de la virtud que conduce al vicio, con lo que es, en este sentido, una crítica de carácter marcadamente ético. ${ }^{22}$ Pero, además, en tercera instancia, la crítica a Maquiavelo se inserta en la tradición del tacitismo ${ }^{23}$ al incidir en que la estrategia para mantener la estabilidad de la república que propone el florentino acaba por derrumbarla. Esta crítica pragmática o política quizá sea la más potente en tanto que señala que la estrategia de Maquiavelo sería auto-contradictoria.

produce en el pensamiento del florentino. Podemos hablar en Gracián de cierto grado de autonomía en sus planteamientos éticos y políticos, pero de ningún modo de la independización de éstos con respecto a la religión como será el caso de Maquiavelo» (Moraleja, 1999, 54). Para una comparación de posibles elementos comunes, véase Cantarino, 2003, 150. Ana Azanza destaca, por su parte, el pesimismo antropológico común a Gracián y Maquiavelo y coincide con Moraleja en lo que concierne al distinto planteamiento de la independencia de la política respecto a la religión, pues para Maquiavelo la fe no pasaría de ser un recurso estratégico más, algo inadmisible para Gracián (Azanza, 2003, 157-158).

22 Maravall encuentra alguna similitud, pese a las diferencias aquí indicadas, entre el concepto de virtud de Gracián con la virtù de Maquiavelo (Maravall, 1984, 344).

23 Gracián, por ejemplo a juicio de Tierno Galván, no sería un tacitista, pero usaría a Tácito para fundamentar su casuística político-moral (en este punto sigo a Novella Suárez, 2003, 196). Sobre esta cuestión véase también J. A. Maravall, «La corriente doctrinal del tacitismo político en España», en J. A. Maravall, Estudios de historia del pensamiento español, Madrid, Ediciones de Cultura Hispánica, 1984. 
Partiendo de estas críticas de Gracián, podemos observar que Schopenhauer tan sólo admitiría como válida la última de ellas, pues en absoluto comparte algo así como un concepto de humanidad cuya degradación política haya de evitarse; en este punto, Schopenhauer no es en modo alguno contrario a la antropología de Maquiavelo. En algunos textos, Schopenhauer le reprocha que quizá su libro El príncipe presuponga un concepto político (de príncipe) de raigambre medieval, pero reconoce que en dicho libro se puede encontrar una colección de consejos prácticos para la vida, al modo de la eudemonología (PP, II, 9, §126). Esto es, elogia a Maquiavelo no como consejero político, sino como autor de un manual de táctica individual para la vida mundana. Claramente, Schopenhauer no comparte el realismo de Maquiavelo que hace de la fuerza y la astucia los criterios decisivos en cuestiones políticas, pero admira su honestidad y aconseja a los hipócritas políticos de su tiempo, que practican el realismo, pero pregonan la bondad y la piedad de sus decisiones políticas, atenerse honestamente sin más a la doctrina de Maquiavelo, con lo cual ganarían credibilidad (PP, II, 9, §124).

Sin embargo, la reflexión de Schopenhauer que nos permite distanciar su posición respecto a Gracián es una nota de aquél en la que excluye la posibilidad de plantear una crítica moral a la propuesta de Maquiavelo, pues la crítica debería plantearse dentro de los límites de la política como disciplina relativamente autónoma de la ética, y sería esta autonomía lo que en el fondo marca distancias entre Schopenhauer y su admirado Gracián:

El problema de Maquiavelo era la solución de la pregunta sobre cómo el príncipe se podía mantener en el trono incondicionalmente, a pesar de enemigos interiores y exteriores. Por tanto, su problema no era de ningún modo el problema ético de si un príncipe, en tanto que ser humano, debía querer eso o no, sino puramente el problema político de cómo, si él lo quisiere, podría lograrlo. A este respecto proporciona Maquiavelo la solución del mismo modo que se escribe una indicación para jugar al ajedrez, con lo que resulta del todo absurdo echar de menos la respuesta a la pregunta de si es moralmente aconsejable en general jugar al ajedrez. Reprochar a Maquiavelo la inmoralidad de su escrito está tan fuera de lugar como reprochar a un maestro de esgrima que no empiece su clase con una lección moral contra el asesinato y el golpe mortal (WWV, I, anexo, 654, nota [583]). 
Aún así, las diferencias entre Schopenhauer y Gracián, pese a los numerosos puntos de contacto e inspiración, no se limitan a este punto, sino que se pueden encontrar en otro aspecto de sus doctrinas.

\subsection{La cuestión ontológica: ser y apariencia}

Como hemos visto en los dos primeros apartados, Schopenhauer y Gracián compartirían, respecto a la sabiduría de la vida, un marco conceptual basado en la tradición clásica sobre la prudencia, la cual motivaría las referencias y la traducción del Oráculo de Gracián por parte de Schopenhauer. Sin embargo, lo que no está del todo claro es si además de estas reflexiones eudemonológicas, habría una afinidad en lo que podría denominarse la ontología de fondo, la teoría sobre la constitución de la realidad como tal. Es innegable que ambos comparten un cierto pesimismo antropológico y social (Moraleja, 1999, 121-122), y que tienen en común el referente cínico como modelo de sabiduría crítica mundana (ver por ejemplo en El Criticón las continuas referencias al cinismo y la búsqueda de lo humano, véase C, I, 6). ${ }^{24}$ De hecho, la visión de los humanos como lobos para los propios humanos que, basada en Plauto, asume Hobbes y en cierto modo también Schopenhauer, se puede encontrar tal cual en Gracián curiosamente el mismo año que se publicó el Leviatán, 1651 (C, I, 4, 99). ${ }^{25}$

Así pues, en cuestiones antropológicas y de sabiduría de la vida, es innegable una afinidad entre ambos. Desarrollando esta afinidad, Neumeister (1991) ha querido extender esta semejanza a la metafísica de ambos, argumentando que en Gracián se puede apreciar también una especie de visión de la realidad como apariencia fugaz e ilusoria. Y puede ser que en cierto modo la letra de la obra de Gracián permita establecer cierto paralelismo con la metafísica de Schopenhauer en tanto que plantea dos dualidades que luego desarrollará el filósofo alemán: ser/apariencia y voluntad/juicio o entendimiento.

\footnotetext{
${ }^{24}$ Para Zimmer, el pesimismo antropológico sería un rasgo compartido por la tradición del moralismo moderno asumido por Schopenhauer, aunque no con la ética antigua, comparativamente más optimista con respecto a la naturaleza humana (Zimmer, 2009, 56-57).

25 José Antonio Maravall muestra el uso del tópico homo homini lupus de Plauto en el Barroco español para destacar el pesimismo antropológico propio de esta época y destaca que su huella se remonta a mucho antes que la referencia de Hobbes (Maravall, 1986, 329-330).
} 
Pero, como señala García Casanova en el Diccionario de conceptos de Baltasar Gracián, la apariencia en la obra del jesuita tiene un triple sentido más allá de lo epistémico, es decir, tiene una connotación normativa (como exigencia ante la incomprensión del mundo), un sentido táctico (para buscar los medios mediante los que lograr sus objetivos) y un tercer aspecto referido a la contemplación, de modo que la realidad no estaría constituida de modo definitivo, sino que sería un proceso continuo y fluido, cambiante. Así, la apariencia, según García Casanova, no se opondría de forma radical a la realidad como tal en sentido fuerte: «la apariencia confirmaría la realidad, como una segunda naturaleza, según lo dicho en el capítulo XXI de El Discreto» (Diccionario, 2005, 61).

De hecho, esta diferencia respecto al concepto de apariencia, pues para Schopenhauer sí que hay una oposición fuerte entre ésta (entendida la apariencia como fenómeno) y la realidad última de la voluntad, conduce a la cuestión sobre la analogía entre individuo y mundo: Gracián dice del individuo humano que es un microcosmos, que comparte la misma estructura que el mundo como tal (C, I, 3, 92), mientras que Schopenhauer procede a la inversa, pero complementariamente, aduciendo que el mundo es un macrántropos, de tal modo que extrapola al mundo alguna de las facultades humanas, en concreto se convierte la voluntad en un concepto ontológico, significando la fuerza ciega y sin sentido que mueve el mundo (WWV, II, §50).

Éste quizá sea uno de los principales puntos de diferencia de Schopenhauer con respecto a Gracián, la conversión de la voluntad de facultad humana en sustancia del mundo: «Abrir los ojos con tiempo. No todos los que ven han avierto los ojos, ni todos los que miran ven. Dar en la cuenta tarde no sirve de remedio, sino de pesar. [...] Es dificultoso dar entendimiento a quien no tiene voluntad, y más dar voluntad a quien no tiene entendimiento» (OP, 230).

En este aforismo se puede apreciar que se considera la voluntad como una facultad individual, transmisible, ciertamente con dificultad, pero ni mucho menos como un rasgo de la esencia de la realidad y que, según Gracián, además requiere de un entendimiento previo, requisito que concede prioridad al intelecto, suponiendo esto una clara distancia con la teoría de la voluntad de Schopenhauer, para quien el entendimiento es un exudado secundario de aquélla. 
Aparte de la distinción entre las facultades del entendimiento y la voluntad, Gracián juega con la dialéctica entre ser y apariencia, propia del Barroco, como una estrategia de su visión crítica de la sociedad, ${ }^{26}$ pero no articula estos dos dualismos tradicionales como hace Schopenhauer equiparando ser y voluntad, e intelecto y apariencia, afirmaciones propias de éste y que limitan el paralelismo entre ambos. Más aún, esta articulación presupone que la voluntad deja de ser una facultad individual para convertirse en un concepto ontológico presente en toda la realidad, con lo cual, como criticará Nietzsche, Schopenhauer habría reificado un concepto que no tenía ese sentido en Gracián y los moralistas franceses. Así pues, pese al pesimismo antropológico y social, y la inspiración en cuestiones eudemonológicas, la afinidad ontológica tendría que limitarse a la analogía del ser humano como mundo en miniatura (microcosmos), pero no podría extenderse a su complementaria (el mundo como macrántropos en Schopenhauer, WWV, II, §50), pues en Gracián no se halla en modo alguno algo así como una voluntad en sentido ontológico.

Como consecuencia de esta diferencia en la metafísica, también el pesimismo de uno y otro albergan ciertas diferencias; según Vossler, el pesimismo sin metafísica de Gracián $^{27}$ está acompañado de un cierto optimismo jovial tanto en su estilo de escritura como en la esperanza de una mejora de la humanidad. Como indica Maravall, en Gracián encontramos la afirmación de la perfectibilidad humana, una perfección que implicaría libertad (Maravall, 1986, 349-352), algo muy alejado del determinismo de Schopenhauer. Y esto parece ser así, además, por la deriva ascética de la metafísica schopenhaueriana de la voluntad: en este caso, la corona del sistema de Schopenhauer es la ética de la compasión, la ascética radical, la negación de la voluntad humana, cosa que no entra dentro del proyecto de Gracián. Según Vossler, pese a su formación jesuítica (o quizá gracias a ella, pues en este punto es cercano a la moral cartesiana), Gracián no comulga con la negación de los afectos, sino que propone su dominio racional por parte del individuo. Incluso la figura del santo del último aforismo del

\footnotetext{
26 Muestra de ello son los aforismos 99 y 130 del Oráculo. En el primero de éstos, se afirma que la mayoría de la gente se fija sólo en la apariencia exterior y pocos son los que se detienen a observar más detenidamente el interior de las cosas, preparando la conclusión que desarrolla en el 130, en el que repite el inicio del aforismo 99: «Las cosas no passan por lo que son, sino por lo que parecen. [...] No tiene su veneración la razón misma donde no tiene cara de tal. [...] La buena exterioridad es la mejor recomendación de la perfección interior» (OP, 130).

27 Según Aranguren, el Barroco español se caracteriza por un juicio negativo sobre el mundo, sin detenerse en su análisis: es enjuiciado como ilusorio antes de ser estudiado a fondo (Aranguren, 1999: 190).
} 
Oráculo se mantiene dentro del plano meramente ético, en el ejercicio de la virtud, no en el de la ascesis, como en Schopenhauer (Vossler, 1935, 347-348). ${ }^{28}$

\section{Conclusiones: moralismo y crítica de la sociedad}

En última instancia, quisiera destacar fundamentalmente dos ideas a modo de conclusión: primero, la necesidad de repensar la relación entre Schopenhauer y la tradición del moralismo moderno, por ejemplo, el vínculo entre Schopenhauer y Baltasar Gracián. Con moralismo me he referido a una serie de autores de ensayos, aforismos, fábulas, tratados y demás géneros textuales con vocación sapiencial (máximas, anécdotas, etc.) y que abordan cuestiones morales desde una óptica mundana, empírica, concreta y casuística entre los siglos XVI-XVIII: Montaigne, La Bruyère, Gracián, La Rochefoucauld o Chamfort, serían ejemplos de esta corriente. En este caso, he querido mostrar la gran influencia, reconocida y convertida en tópico, de Gracián sobre Schopenhauer, pero también hacer un balance crítico en la medida en que si bien hay una fuerte afinidad en el aspecto central de la sabiduría mundana, esto no obsta para que haya algunas distancias tanto en el calado filosófico del pesimismo (para Schopenhauer la visión trágica de la existencia tiñe toda su filosofía, mientras que en el caso de Gracián queda todavía un resquicio para la esperanza de una mejora humana) como en la consideración última de las dicotomías voluntad-razón y realidad-apariencia, dicotomías que Schopenhauer lleva a un extremo que no es compartido por el planteamiento de Gracián, imbuido de una cierta confianza en el logro de la virtud mediante el uso de la razón. ${ }^{29}$

También, en segundo lugar, quisiera reivindicar la tradición prudencial del moralismo, a veces considerada periférica en la historia de la filosofía. En el fondo de la reflexión mundana sobre la vida cotidiana que nos ofrecen autores como Gracián,

\footnotetext{
${ }^{28}$ Blumenberg interpreta la irrupción de la figura del santo en el último aforismo de OP de Gracián como una identificación entre arte de vivir y religión, de modo que cancelaría en gran medida parte de las tesis expuestas con anterioridad (Blumenberg, 2000, 123). Sin embargo, considero que la noción de santidad expuesta por Gracián en ese texto no se puede identificar sin más con la noción popular de santo, sino que, como indica Vossler, tendría más que ver con la virtud ética, concepto desarrollado en dicho aforismo 300 de OP.

29 En este sentido Blumenberg se replantea la relación entre moralismo e Ilustración y considera que Gracián va más allá de ésta, pues predominaría en su obra un cierto espíritu de resignación de lo finito, la humanidad, frente a lo infinito, lo divino (Blumenberg, 2000, 121).
} 
Montaigne, Voltaire, La Rochefoucauld o Chamfort, laten conceptos e ideas de gran calado, demostrando que la filosofía como tal puede disponer de un gran atractivo entre el gran público, hecho que mostraría que desde la filosofía podemos abordar cuestiones aparentemente cotidianas y concretas con una óptica crítica, enriquecedora y reflexiva. El uso del aforismo bien cincelado y del ensayo breve por parte de Gracián y Schopenhauer muestra cómo la forma de expresión y planteamiento de los problemas está ligada a un punto de vista crítico y reflexivo propio de la filosofía, y que ésta no pierde dignidad, sino que muestra su relevancia al abordar cuestiones mundanas como la fama, el valor, el ingenio, el amor, etc., con la potencia, el rigor y el calado que le serían propios.

Más aún, en el caso de Schopenhauer esta forma de hacer filosofía no es en modo alguno un añadido posterior a su filosofía sistemática, sino que, como lo muestran sus póstumos de juventud, las reflexiones sobre la sabiduría mundana emergen a la vez y prácticamente entrelazadas con las ideas respecto a la naturaleza de la cosa en sí como voluntad. Incluso, como sugiere Nietzsche, precisamente encontró en la tradición del moralismo la respuesta a la incógnita sobre la cosa en sí de Kant, esto es, tomando el moralismo como modelo pudo entenderla como voluntad a partir de una analogía entre el cuerpo humano y el resto del mundo (WWV, I, §6). Ahora bien, además de estar entrelazadas desde su origen, la sabiduría mundana inspirada en Gracián cumple una función crucial en el sistema filosófico de Schopenhauer, pues al elevar el nivel de exigencia moral de su ética de la compasión a la renuncia total propia de un asceta, él mismo es consciente de la necesidad ofrecer una vía alternativa, también marcada por sus supuestos ontológicos y no exenta de dificultades y tensiones.

Por tanto, la reivindicación de la tradición filosófica orientada a la sabiduría mundana tendría así al menos un doble propósito. Primero, mostrar que la filosofía es capaz de abordar con rigor y capacidad crítica una temática a veces considerada menor desde la filosofía más académica. Pero también, por último, quisiera evidenciar que justamente esas temáticas propias de una tradición de una filosofía mundana, considerada a veces periférica, nos conducen a los problemas fundamentales de la filosofía, como lo mostraría el caso de la filosofía schopenhaueriana. Como habría indicado con la cita de Nietzsche al inicio de este ensayo, los conceptos fundamentales de la metafísica schopenhaueriana, tendrían su origen precisamente en la reflexión filosófica sobre la sabiduría mundana. Así, la teoría sobre la sabiduría de la vida no sólo 
no supondría un anexo a su metafísica, sino que podría considerarse el germen a partir del cual se desarrolla el resto de su pensamiento.

\section{Bibliografía}

ArAnguren, J. L. (1993). «La moral de Gracián», Estudios literarios, Barcelona: Círculo de Lectores.

AYALA, Jorge M. (ed.) (1993). Baltasar Gracián, Barcelona: Anthropos (Suplemento, 37).

— (2003). «Un arte para el ingenio: el desafío de Baltasar Gracián», en J. Fco. García Casanova (ed.), El mundo de Baltasar Gracián, Granada: Universidad de Granada.

AZANZA ELÍO, Ana (2003). «Política y sociedad en Gracián», en J. Fco. García Casanova (ed.), El mundo de Baltasar Gracián, Granada: Universidad de Granada.

BlumenBerG, Hans (2000). «Codificación y desciframiento del mundo humano», La legibilidad del mundo, trad. de Pedro Madrigal, Barcelona: Paidós.

CANTARINO, Elena (2003). «Sobre el Oráculo manual y Razón de Estado», en J. Fco. García Casanova (ed.), El mundo de Baltasar Gracián, Granada: Universidad de Granada.

— (2011). «Gracián y Schopenhauer. La gran sindéresis o die grosse Obhut seiner selbst» en F. Oncina (ed.): Schopenhauer en la historia de las ideas, Madrid: Plaza y Valdés.

CANTARINO, Elena y Blanco, Emilio (coords.) (2005). Diccionario de conceptos de Baltasar Gracián, Madrid: Cátedra.

García CASAnOva, Juan Fco. (ed.) (2003). El mundo de Baltasar Gracián, Granada: Universidad de Granada.

GRACIÁN, Baltasar (1980). El Criticón, ed. de Santos Alonso, Madrid: Cátedra.

— (1995). Oráculo manual y arte de prudencia, ed. de Emilio Blanco, Madrid: Cátedra.

GuellouZ, S. (1993). «Gracián en la Francia del siglo XVII» en J. Ayala (ed.), Baltasar Gracián, Barcelona: Anthropos (Suplemento, 37).

HÜBSCHER, A. (1985). «Einleitung», Der handschriftliche Nachlass, 4, II, München: DTV.

JiMÉNEZ MorenO, L. (1993). «Presencia de B. Gracián en filósofos alemanes: Schopenhauer y Nietzsche», en J. Ayala (ed.), Baltasar Gracián, Barcelona: Anthropos (Suplemento, 37). 
KRAUSS, W. (1962). La doctrina de la vida según Baltasar Gracián, Madrid: Rialp.

Losada PAlenzuela, José Luis (2011). Schopenhauer traductor de Gracián. Diálogo y formación, Valladolid: Univ. de Valladolid.

MARAVALL, J. M. (1984). «Antropología y política en el pensamiento de Gracián», en Estudios de historia del pensamiento español, III, Madrid: Ediciones Cultura Hispánica.

— (1986). La cultura del Barroco. Análisis de una estructura histórica, Barcelona: Ariel.

MARCIN, Raymond B. (2006). In Search of Schopenhauer's Cat: Arthur Schopenhauer's Quantum-Mystical Theory of Justice, Washington, D.C.: Catholic University of America Press.

Moraleja JuÁRez, A. (1999). Baltasar Gracián: forma política y contenido ético. Madrid: Ediciones de la UAM.

NeumeISTER, S. (1991). «Schopenhauer als Leser Gracians» en S. Neumeister y D. Briesemeister (eds.), El mundo de Gracián. Actas del Coloquio Internacional de Hispanistas (Berlín, 1988). Berlín: Bibliotheca Ibero-Americana, Colloquium Verlag.

- (1993). «Gracián en Alemania», en J. Ayala (ed.), Baltasar Gracián, Barcelona: Rev. Anthropos (Suplemento, 37).

NiETZsCHE, F. (1999). Kritische Studienausgabe, hrsg. von G. Colli und M. Montinari, Berlin: DTV - Walter de Gruyter.

Novella SuAREZ, J. (2003). «Baltasar Gracián y el arte de saber vivir», en J. Fco. García Casanova (ed.), El mundo de Baltasar Gracián, Granada: Universidad de Granada.

SAFRANSKI, R. (2001). Schopenhauer und die wilden Jahre der Philosophie, Frankfurt a.M.: Fischer.

SCHOPenHAUER, A. (1985). Der handschriftliche Nachlass. 5 Bänden, München: DTV.

— (1987). Gesammelte Briefe, hrsg. von Arthur Hübscher, Bonn: Bouvier.

— (1988). Werke in fünf Bänden, hrsg. von L. Lütkehaus, Zürich: Haffmans Verlag.

- (2003). El mundo como voluntad y representación. II, Complementos, trad. de P. López de Santa María, Madrid: Trotta.

- (2004). El mundo como voluntad y representación, I, trad. de P. López de Santa María, Madrid: Trotta.

— (2006). Parerga y Paralipómena, I, trad. de P. López de Santa María, Madrid: Trotta. 
SPIERLING, V. (1994). Arthur Schopenhauer. Philosophie als Kunst und Erkenntnis, Zürich: Haffmans.

VOSSLER, K. (1935). «Introducción a Gracián», Revista de Occidente, 46.

ZIMMER, R. (2009). «Philosophie der Lebenskunst aus dem Geist der Moralistik. Zu Schopenhauers Aphorismen zur Lebenweisheit». Schopenhauer-Jahrbuch, 90: 45-64.

— (2010). Arthur Schopenhauer. Ein philosophischer Weltbürger, München: DTV.

Recibido: 13/02/2013

Aceptado: 18/05/2013 